\title{
ORIGINAL
}

\section{VIGILANCIA EPIDEMIOLÓGICA DE LA GRIPE (H1N1) 2009 SIN RED CENTINELA}

\author{
Alberto Malvar Pintos, M. ${ }^{a}$ Jesús Purriños Hermida y Xurxo Hervada Vidal \\ (1) Servicio de Epidemiología de la Dirección Xeral de Saúde Pública e Planificación. Santiago de Compostela.
}

\section{RESUMEN}

Fundamento: En Galicia no existe red centinela de vigilancia epidemiológica por lo que se utilizan sistemas alternativos de vigilancia. El objetivo de este trabajo es describirlos y presentar los resultados observados durante la pandemia de gripe (H1N1) 2009.

Métodos: Los sistemas utilizados fueron llamadas recibidas por gripe (H1N1) 2009 e infección respiratoria aguda en el 061, sistema de notificación de enfermedades obligatorias (SXNOE), vigilancia virológica, registros de atención primaria e ingresos hospitalarios. Los datos se analizaron con Excell.

Resultados: La primera onda por virus $\mathrm{A}(\mathrm{H} 1 \mathrm{~N} 1) \mathrm{v}$ se registró a través del 061 entre las semanas 39/2009 y 49/2009, alcanzando el pico en la 44/2009 con la mayor tasa de llamadas acumuladas en el grupo de 5-19 años. SXNOE proporcionó una onda (semanas 39/2009 a 49/2009) con pico en la 44/2009. Microbiológicamente se estudiaron con RT-PRC 6.181 muestras (31\% positivas y pico en la semana 44/2009). Los registros de Atención Primaria proporcionaron una onda (semanas 39/2009 a 49/2009) con pico en la semana $44 / 2009$ con la mayor tasa de consultas para los de 5-19 años. Entre las semanas 26/2009 y 17/2010, ingresaron 698 personas con gripe (H1N1) 2009, con mayor número de hospitalizaciones en la 44/2009.

Conclusiones: Los sistemas descritos quedan avalados por la homogeneidad de los resultados, ya que dibujan la misma onda (semanas 39/2009 a 49/2009) y coinciden en el pico (semana 44/2009) donde se observa la mayor tasa de consultas entre 5-19 años. El 061 aparece como el sistema más operativo al proporcionar datos diarios.

Palabras clave: Pandemia. Subtipo H1N1 del Virus de la Influenza A. Vigilancia en salud pública.

\section{ABSTRACT \\ Epidemiological Surveillance of Influenza (H1N1) 2009 without Sentinel System}

Background: The objective is to explain the Galician influenza surveillance system and to present the results observed during the pandemic flu, where due to the lack of sentinel surveillance practices, other alternatives are used.

Method: Data was collected from: 061 phone calls for flu and acute respiratory illness; notifiable diseases usual reporting system (SXNOE); virological surveillance; primary care and hospital records and was analyzed with Excell.

Results: The first epidemic wave for $\mathrm{A}(\mathrm{H} 1 \mathrm{~N} 1) \mathrm{v}$ according to 061 data was between week $39 / 2009$ and 49/2009, and it peaked in week $44 / 2009$, with a greater rate of accumulated calls was in the 519 age group. SXNOE showed a wave (week 39/2009 to 49/2009) and peaked in week 44/09. Virological surveillance included 6.181 samples with PCR-RT $(31 \%$ were positive and peaked in week 44/09). Primary care registers showed a wave (week 39/2009 to $49 / 2009$ ) which peaked in week $44 / 09$ with the greatest rate of consultations was in the 5-19 age group. Between week 26/09 and week $17 / 2010,698$ patients were admitted with $\mathrm{A}(\mathrm{H} 1 \mathrm{~N} 1) \mathrm{v}$, with the highest hospitalization in week 44/09

Conclusions: The validity of the described surveillance systems is supported by the homogeneity of results, and they produced an equivalent wave (weeks $39 / 2009$ to $49 / 2009$ ) which peaked in week $44 / 2009$ and showed the highest rate of consultations in the 5-19 age group. The 061 appears to be the most practical system to provide daily data.

Key words: Pandemic. Influenza A Virus, H1N1 Subtype. Population Surveillance.

Correspondencia:

Alberto Malvar Pintos

Edificio Administrativo de San Lázaro s/n

15703 Santiago de Compostela (A Coruña)

alberto.malvar.pintos@sergas.es

Los autores del texto no tienen ningún conflicto de interés. 


\section{INTRODUCCIÓN}

La vigilancia de la gripe en España se lleva a cabo integrando datos epidemiológicos y de laboratorio desde mediados de los años noventa, con el inicio del funcionamiento de la red centinela ${ }^{1}$, del que forman parte prácticamente todas las comunidades autónomas españolas salvo Galicia y Murcia.

Periódicamente aparece un nuevo virus de gripe A diferente y, cuando esto ocurre, hay dos preguntas fundamentales: cuál es el grado de protección de la población (si hay alguno) y cuál es el espectro de la enfermedad clínica y su posible impacto en los servicios sanitarios, para quienes los sistemas de vigilancia son fundamentales como mecanismos de alerta de la situación.

De este modo, la declaración de pandemia por parte de la OMS el 11/06/09 tras la aparición de un nuevo virus $\mathrm{A}(\mathrm{H} 1 \mathrm{~N} 1) \mathrm{v}$, detectado por primera vez en abril de $2009^{2}$ y genética e inmunológicamente diferente a los virus AH1N1 que estaban circulando entre humanos en las últimas décadas ${ }^{3}$, motivó que la vigilancia de la gripe se viese sujeta a ciertos cambios, con la incorporación en cada comunidad autónoma de nuevos sistemas de vigilancia tales como el registro de casos ingresados con el virus de la gripe $\mathrm{A}(\mathrm{H} 1 \mathrm{~N} 1) \mathrm{v}$ o de éxitus relacionados con este nuevo virus.

El objetivo de este trabajo es dar a conocer los sistemas de vigilancia de la gripe establecidos en Galicia y presentar los resultados observados durante la pandemia de gripe.

\section{MATERIAL Y MÉTODOS}

Hasta el año 2009 en Galicia la actividad gripal se vigilaba con las llamadas recibidas por gripe e Infección Respiratoria Aguda (IRA) en el 061, datos que se validaban a posteriori con el registro de enfermedades de declaración obligatoria (SXNOE) y se completaban con la vigilancia virológica.
El SXNOE recoge los casos de gripe como EDO numérica, sin emplear ninguna definición de caso concreta. Este sistema presenta un retraso estructural que imposibilita su uso para analizar los datos semana a semana durante la temporada de gripe.

La vigilancia de la gripe con el registro de llamadas al 061 comenzó en Galicia en la temporada 2000/01. Hasta la temporada 2008/09, la vigilancia estaba en activo sólo durante la temporada de gripe (semana 40 de un año a la 19 del año siguiente), pero tras la alerta mundial producida por la aparición del nuevo virus $\mathrm{A}(\mathrm{H} 1 \mathrm{~N} 1) \mathrm{v}$ se decidió mantener la vigilancia de manera indefinida.

Este sistema se lleva a cabo con la recepción diaria en el Servicio de Epidemiología de la DXSPeP (Dirección Xeral de Saúde Pública e Planificación) de todas las llamadas recibidas en el 061 y codificadas como gripe, IRA o fiebre. De todos modos, para establecer el nivel de intensidad de la actividad gripal se emplean sólo las llamadas por gripe e IRA, ya que un estudio realizado (Servicio de Epidemiología. DXSPeP. Documento interno) detectó que era el mejor método para establecer el inicio de la onda de gripe y predecir su pico.

Los datos registrados en cada llamada son: código de la enfermedad, edad en años y sexo del paciente, ayuntamiento al que pertenece el sujeto y fecha de llamada.

Desde la semana epidemiológica 35/2009, estos datos se utilizan además para clasificar la actividad gripal, según los criterios de la Red Española de Vigilancia de la Gripe, en función de su intensidad, difusión y tendencia. Los niveles para ello se establecieron de manera empírica en base a experiencias de años previos, excepto para el umbral que separa los niveles de intensidad alta y muy alta, para los que se aplicó al umbral basal la razón entre el umbral epidémico y el umbral basal del Reino Unido. Para estudiar la difusión se emplearon las provincias, cada una 
con un umbral propio, considerando afectada el $50 \%$ de la población gallega cuando se supera el umbral en A Coruña y Pontevedra.

El tercero de los sistemas de vigilancia de la gripe utilizados hasta ahora es la vigilancia microbiológica. Este sistema de vigilancia se nutre de los datos de tres hospitales, el de Ourense y el de Vigo (cuya información se remite semanalmente al ISCIII como parte del Sistema de Vigilancia de la Gripe en España) y el de Coruña. Ahora bien, a raíz de la nueva situación pandémica se amplió hasta 6 el número de hospitales gallegos en los que se puede verificar por PCR las muestras respiratorias de los casos con sospecha de presentar gripe.

La información se envía diariamente al Servicio de Epidemiología con las siguientes variables: número de historia clínica, edad, sexo, tipo de muestra y resultado obtenido por PRC para virus A y PRC específica para nuevo virus.

La sistemática de toma de muestras fue variando según la situación. Para la detección de transmisión comunitaria sostenida (TCS) se implantó en los hospitales públicos, en la semana epidemiológica $25 / 09$, un sistema de recogida de muestras de todos los pacientes que cumplían una definición de caso de gripe y requerían ingreso $\mathrm{y}$, a mayores, a diario, de dos casos en menores de 60 años que acudiesen a urgencias (tuviesen o no indicado tratamiento). Este sistema estuvo en activo hasta finales de julio, cuando pasó a recomendarse la toma de muestra en los ingresados y los pacientes de urgencias que necesitasen tratamiento con antivirales. En la semana 44/2009 se cambiaron nuevamente las indicaciones y se pasó a tomar muestras solamente de los casos ingresados.

Ahora bien, a estos tres sistemas de vigilancia (SXNOE, 061 y vigilancia microbiológica) se añadieron, a raíz de la declaración de pandemia de gripe, nuevos sistemas de vigilancia de la gripe: registros de consultas de Atención Primaria y de los ingresos hospitalarios. También se comenzó a trabajar con las urgencias atendidas en hospitales, las ausencias de los colegios y el formulario de autodiagnóstico de gripe que la Consellería de Sanidade colgó en su web (estos últimos sistemas están aún pendientes de evaluar).

La informatización de los centros de salud en Galicia está establecida por distintas aplicaciones (OMI, SIG@P y IANUS, que es el más extendido) que permiten registrar los casos atendidos de gripe de manera específica con el código R80 de la CIAP. A mayores, en la semana epidemiológica 39/2009, el SERGAS implantó en su aplicativo un formulario para registrar casos de gripe y/o prescribir antivirales, que dio por obligado cumplimiento dejando a voluntad del médico el registro por el método habitual.

Todos los lunes, el servicio de informática del SERGAS le manda al Servicio de Epidemiología un archivo tanto con los registros de R80 como del nuevo formulario. En este archivo se recoge: identificador del médico $\mathrm{y}$ otro del paciente, centro de notificación, fuente (R80 o formulario), edad y sexo del paciente, ayuntamiento y provincia de residencia y fecha de registro.

La implantación del formulario supuso un cambio en la frecuencia de registro que originó cierta inestabilidad en el sistema. Por ello, para el seguimiento de la gripe pandémica se decidió utilizar un número restringido de médicos que cumpliesen los siguientes requisitos: ser los que más casos registraron entre las semanas $45 / 2008$ y la $15 / 2009$, poniendo el punto de corte en el $73 \%$ de los registros acumulados, y que declararan algún episodio entre las semanas 28 y 41 de 2009.

En lo que se refiere a la vigilancia de los casos ingresados por o con gripe confirmada por laboratorio con RT-PCR, comenzó en la semana epidemiológica 26/2009. Las primeras recomendaciones establecidas, orienta- 
das a ingresar a todo paciente con gripe $\mathrm{A}(\mathrm{H} 1 \mathrm{~N} 1) \mathrm{v}$, cambiaron a finales de mayo cuando se pasó a ingresar sólo aquellos casos en los que el cuadro clínico así lo recomendase y, de este modo, este sistema pasó a ser el principal indicador de gravedad de enfermedad. Se basa en una notificación, inicialmente diaria y semanal desde enero de 2010, en la que se registran: hospital, número de historia, fecha de ingreso, edad, sexo, presencia o no de factores de riesgo, planta, UCI (con fecha de ingreso y alta) y necesidad o no de ventilación mecánica, éxitus y fecha de alta. La base se remite aunque no haya casos ingresados. Estos datos se complementan con una ficha ad hoc. Esta notificación continúa en la actualidad vigente con participación del 100\% de los hospitales gallegos públicos y una buena representación de privados. El formulario de notificación es diferente según se declare un ingreso o un éxitus, que requieren de una ficha más exhaustiva, propuesta por el Grupo de Trabajo de Vigilancia.

Los datos de población con los que se calcularon las tasas proceden del padrón y se refieren siempre a cien mil habitantes.

Por onda se entiende el periodo que abarca el pico $+/-5$ semanas.

\section{RESULTADOS}

Con los datos registrados por el 061 se observó inicialmente una pequeña onda de corta duración, coincidiendo con la alerta mundial (semana 17), tras la que las notificaciones fueron paulatinamente descendiendo hasta la semana 25/09 (finales de junio), cuando comenzó un discreto aumento progresivo. La primera onda epidémica por el nuevo virus $\mathrm{A}(\mathrm{H} 1 \mathrm{~N} 1) \mathrm{v}$ se presentó antes de lo que se suele ser habitual en Galicia, alcanzando el pico ( $\mathrm{N}=1.057$ llamadas por gripe e IRA) en la semana 44/09 (figura 1). Además, la intensidad de la onda superó a las observadas en temporadas previas (figura 1), donde se recogen también las temporadas 2001/02 y $2008 / 09$, que eran las que presentaron hasta ahora las mayores intensidades desde que se implantó la vigilancia por el 061 .

Como todos los años, se detectó una mayor demanda de consultas telefónicas en A Coruña y Pontevedra, con un nivel de intensidad que aumentó prácticamente el doble en comparación con la onda de la temporada 2008/09 (pico +/- 5 semanas): A Coruña 271 versus 143 y Pontevedra 263 versus 130 llamadas por $10^{5} \mathrm{~h}$. Por provincias, el pico de la onda se presentó en Ourense una semana más tarde que en el resto de las provincias gallegas.

En lo que se refiere a grupos de edad (0-4; $5-19 ; 20-44 ; 45-64 ; 65+)$, lo habitual era encontrar durante todo el año las tasas más elevadas en los niños menores de 5 años, seguido por el grupo de más de 64 años y, respecto al resto del año, durante la onda epidémica se observaba un descenso por debajo del $20 \%$ en la frecuencia de llamadas recibidas por los menores de 20 años. Con la gripe $\mathrm{A}(\mathrm{H} 1 \mathrm{~N} 1) \mathrm{v}$ cambiaron ambas características: la mayor frecuencia de llamadas acumuladas en onda se encontró en el grupo de edad de 0-4 años (857 llamadas por $10^{5} \mathrm{~h}$ ), seguido del grupo de edad de 5-19 años (690 llamadas por $10^{5} \mathrm{~h}$ ). Por otra parte, el porcentaje de llamadas en los menores de 20 años aumentó hasta alcanzar en la semana 43/2009, con 1014 llamadas totales por gripe e ira, un $60 \%$.

Se observó también que no coincidieron los picos en los distintos grupos de edad. Primero lo alcanzaron los de 5 a 19 años (semana epidemiológica 43/2009) y después, conjuntamente, los de 20 a 64 (semana $44 / 2009$ ). Con cierto retraso alcanzaron el pico de la onda los mayores de 64 años (semana 52/2009).

El registro de SXNOE proporcionó una onda de intensidad media baja y se apreció menor intensidad que la de la onda del 
Figura 1

Número de llamadas por gripe (H1N1) 2009 e IRA recibidas en el 061 durante el periodo comprendido desde la semana 40/08 hasta la semana $15 / 10$ y en la temporada 2001/02 (que se presenta dos veces). Se acompaña de la mediana de las temporadas $2006 / 08$ para las semanas que están fuera de la temporada de gripe, $y$ de los niveles de intensidad de actividad gripal

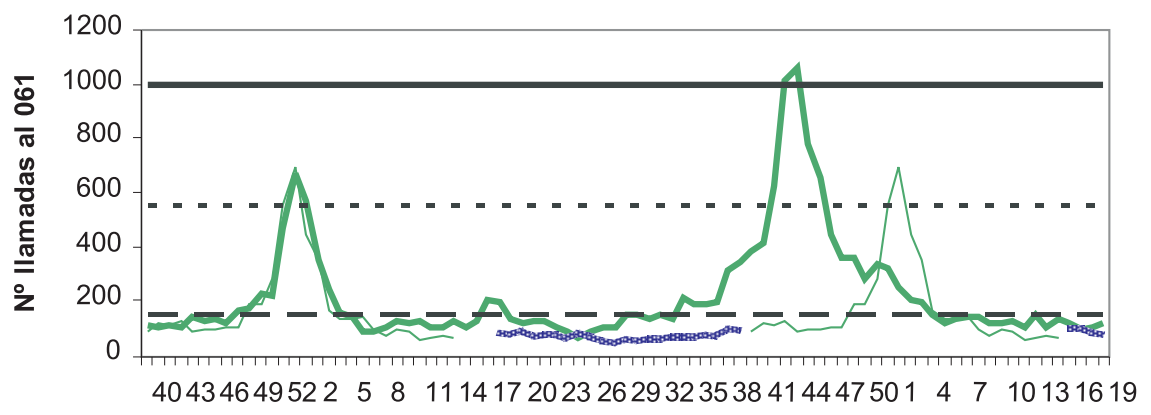

\begin{tabular}{|lcc|}
\hline 2008/2009/2010 & 2001/2002 \\
— - Intensidade media & - - - . Intensidade elevada & Moi elevada \\
\hline
\end{tabular}

2008/09, empleando como indicador el número de casos declarados/declarantes; en ésta se declararon 3,0 casos/semana, mientras que en el 2009 fueron 2,4. El pico de la onda se estableció en la semana 44/09 (en la $43 / 09$ para los pediatras $(\mathrm{N}=2.164)$ y en la $44 / 09$ para los médicos de familia $(\mathrm{N}=3.213)$ y para el conjunto de ambos tipos de declarante). De hecho, este indicador presentó una marcada distribución etárea debida a la diferencia entre los declarantes pediatras y médicos de familia. Así, en la figura 2 se observa que el número semanal de casos/declarantes entre los pediatras fue, durante la onda de 2009, muy superior a la de los médicos de familia y así, el número medio de casos declarados en estos dos grupos fue en A Coruña de 6 versus 2,9; en Lugo, de 7,3 versus 1,3; en Ourense, de 2,4 versus 1,3; y, por último, en Pontevedra, 7,4 versus 3,3. Además, al compararlo con la onda de 2008/09 se observó que la declaración pediátrica se multiplicó por 2,7 (3.782 casos en la onda 2008/09 y 10.206 en la onda pandémica) mientras que la de los médicos de familia disminuyó un 43\% (35.515 versus 21.619).

En lo referente a la vigilancia microbiológica, desde la semana 26/09 a la 15/2010 se estudiaron con RT-PRC 6.181 muestras, de las que el $31 \%$ fueron positivas. Desde la semana 38/2009 el porcentaje de positivos comenzó a ascender hasta alcanzar el pico en la semana 44/2009 (374 muestras positivas de 661 totales), a partir de la cual comenzó a descender progresivamente hasta la semana 48/2009 (46 muestras positivas de 278 totales) (figura 3).

El 22\% de las muestras se analizaron antes de la onda (1390), 64\% durante la onda (3978) y el 13\% (812) que resta después de la onda. La positividad fue del $27 \%, 37 \%$ y $5 \%$ respectivamente. El mayor porcentaje de 
Figura 2

\begin{abstract}
Número semanal de casos de gripe (H1N1) 2009 declarados al SXNOE en Galicia desde la semana 40/2001 hasta la semana 15/2010 por tipo de declarante: médico de familia o pediatra
\end{abstract}

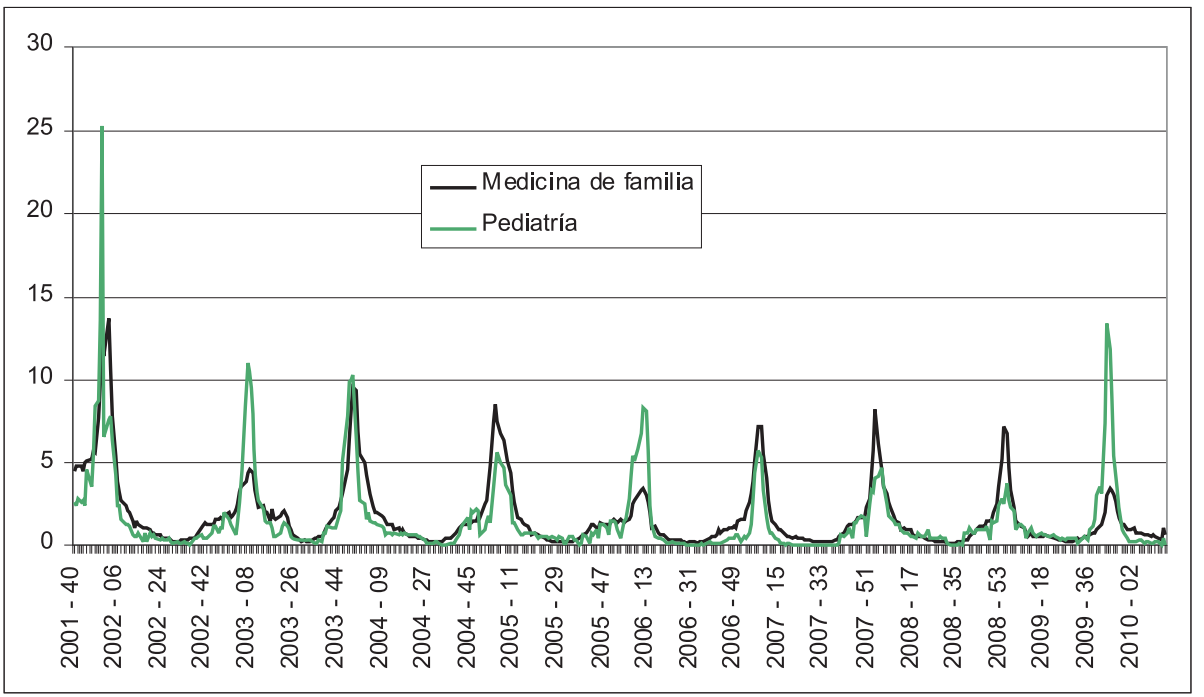

positividad se observó en el grupo de 5-19 años (65\% de 930), seguido por el grupo de $20-44$ años (34,7\% de 1872). El de menor porcentaje de positividad fue el grupo de 65 años en adelante $(9,4 \%$ de 1299$)$.

Los registros de Atención Primaria facilitados por el SERGAS proporcionaron una onda epidémica con el pico alcanzado en la semana 44/09; así coincidió en todas las provincias gallegas excepto en Ourense, donde el pico se presentó una semana más tarde. En la figura 4 se observa como el comportamiento de los episodios de gripe reprodujeron en tiempo y forma las llamadas del 061 por gripe e IRA, aunque con valores diferentes.

No se observó la pequeña onda primaveral registrada a través de las llamadas al 061. Las consultas por edad que presentaron la mayor tasa es el grupo de 5-19 años (con valores en onda de 7359 episodios de gripe registrados por $10^{5} \mathrm{~h}$ por el grupo restringido de médicos acumulados durante las semanas 39-49). La intensidad de la onda de 2009 fue sólo ligeramente superior a su precedente, la del 2008/09 (3.550 versus 2.723) (figura 4).

Por otro lado, desde la semana 26/09 a la 17/2010, en Galicia se registraron 698 ingresos con gripe $\mathrm{A}(\mathrm{H} 1 \mathrm{~N} 1) \mathrm{v}$, que supusieron una tasa bruta de 25 ingresos por cien mil habitantes, y fue en la semana 44/09 aquella en la que se notificó el mayor número de casos hospitalizados, con una tasa bruta de 4,3/10.000 h. Considerando la onda de 11 semanas, las mayores tasas de ingreso fueron para el grupo de edad de 0-4 años y los valores más bajos para el grupo de más de 64 años. Un $12 \%$ de las personas ingresadas por gripe requirieron asistencia en la unidad de cuidados intensivos, lo que supuso una tasa de ingresos en UCI de 3,1 pacientes/UCI por cien mil h.

En Galicia se declararon durante este periodo un total de 17 éxitus con gripe con- 
Figura 3

Número de muestras estudiadas para el virus (H1N1) 2009 en Galicia y porcentaje de muestras positivas desde la semana 30/2009 hasta la 12/2010

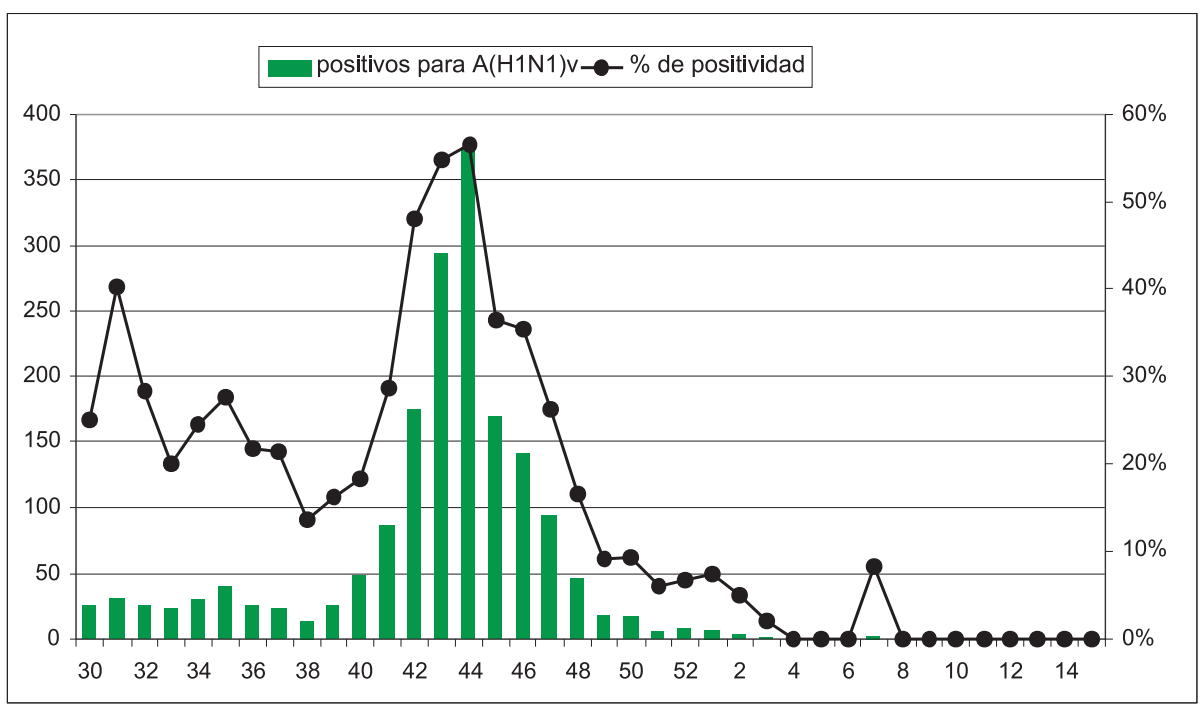

Figura 4

Número de episodios de gripe (H1N1) 2009 registrados en las aplicaciones del Sergas en atención primaria por el grupo restringido de médicos desde la semana 40/07 a la semana 13/10

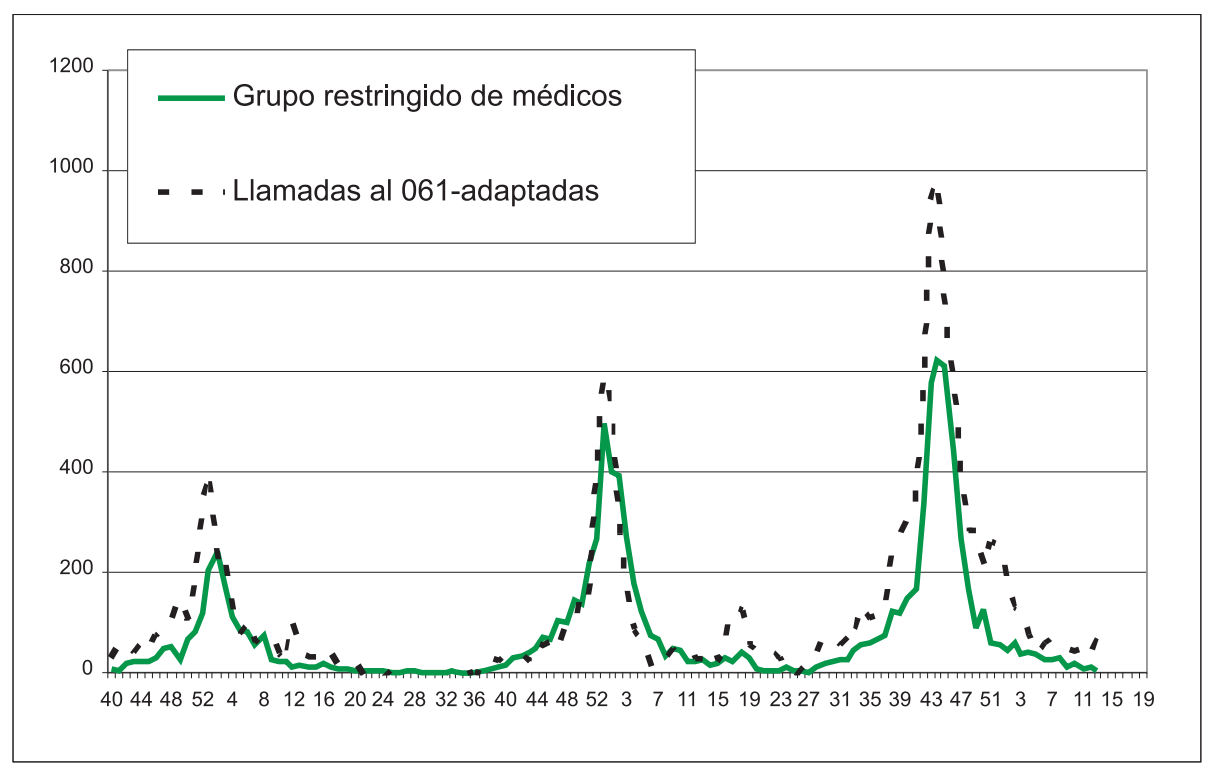


Evolución temporal de la onda de gripe (H1N1) 2009 según datos recogidos por los diferentes sistemas de vigilancia de la gripe establecidos en Galicia (eje $\mathrm{X}=$ semanas epidemiológicas)

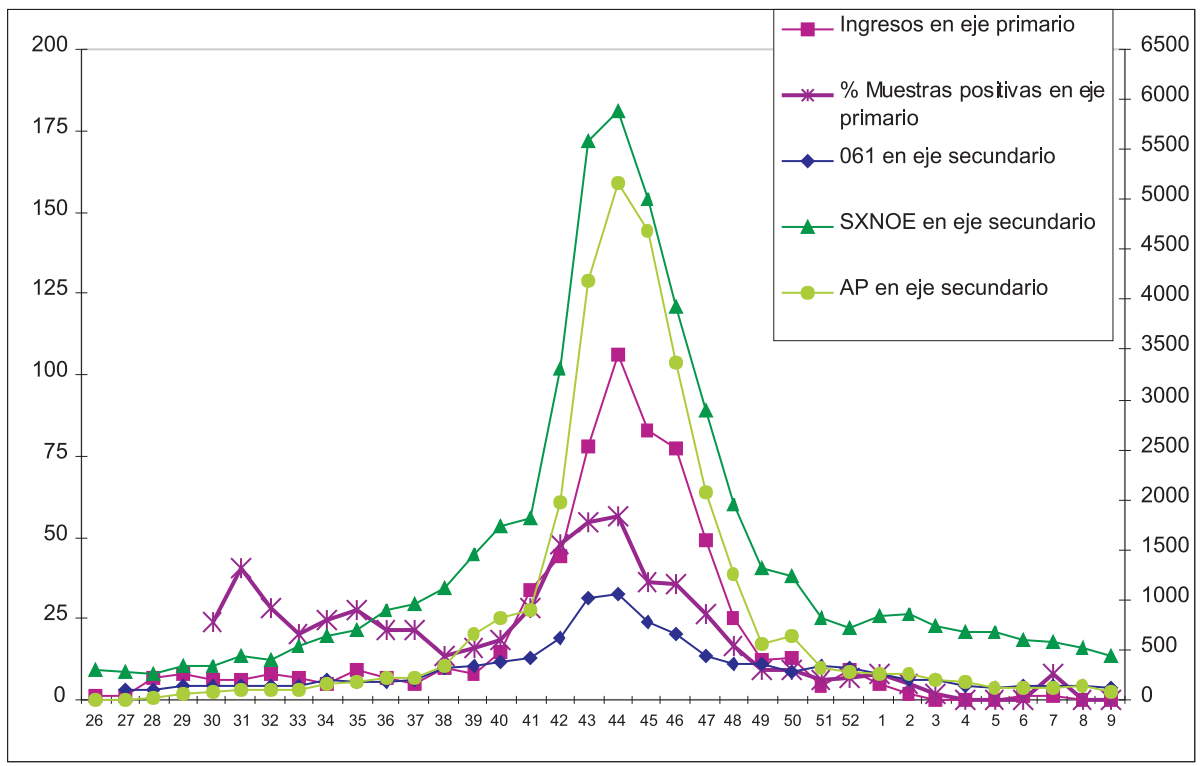

firmada por laboratorio, lo que se tradujo en una tasa bruta de 0,6 por $100.000 \mathrm{~h}$. y una letalidad entre los ingresados de un $2,4 \%$. Por grupos de edad se observó que la mayor tasa de mortalidad se correspondió al grupo de más de 64 años.

La concordancia de los resultados de la vigilancia efectuada por los diferentes sistemas queda reflejada en la figura 5.

\section{DISCUSIÓN}

En Galicia, la circulación del nuevo virus $\mathrm{A}(\mathrm{H} 1 \mathrm{~N} 1) \mathrm{v}$ dio lugar a una primera curva pandémica en la que se observó que el grupo de 64 años en adelante presentaba la menor tasa de llamadas por gripe e IRA al $061^{4}$, algo especialmente relevante en Galicia por el gran porcentaje de población envejecida que tiene. Estos resultados concuerdan con lo observado con los primeros datos epide- miológicos disponibles, que sugerían que la población de mayor edad podría presentar un menor riesgo de enfermar ${ }^{5}$, y que se confirmó al observar que un tercio de la población de EEUU de más de 60 años tenían anticuerpos frente a este nuevo virus (probablemente por contacto previo con virus derivados del AH1N1 del 1918), y que fue también corroborado en Japón ${ }^{6}$ y Finlandia ${ }^{7}$, aunque en estos lugares quedaba prácticamente limitada a los nacidos antes de 1930.

Otro hallazgo relevante fue la heterogeneidad geográfica en la tasa de infección observada en Galicia, con el retraso en la onda en la provincia de Ourense ${ }^{4}$, que podría sugerir una transmisibilidad no muy elevada, y que se había observado también en Inglaterra ${ }^{8}$.

Por otro lado, en Galicia, la tasa bruta de ingresos hospitalarios observada durante la primera onda de $\mathrm{A}(\mathrm{H} 1 \mathrm{~N} 1) \mathrm{v}$ y la distribución 
etárea de los ingresados se encontró dentro de los valores esperados en función de los datos observados en el hemisferio sur donde se registró una tasa bruta de ingresos que no superó, en poblaciones grandes, los $25 \mathrm{i} / 100.000 \mathrm{~h}$, con las mayores tasas de ingresos en niños de 4 años y las menores en mayores de 65 años.

Además, la tasa bruta de ingresos en UCI y la proporción que supusieron sobre el total de personas ingresadas se mantuvieron también dentro de los valores esperados, en función nuevamente de los datos observados en el hemisferio sur, donde las tasas de ingreso en UCI no habían superado los 3uci/100.000h-onda, con lo que el porcentaje de los que necesitaron asistencia en este servicio varió entre un 10-20\%. Estas premisas se cumplieron en Galicia excepto para el grupo de más de 64 años, en los que la proporción de ingresados en UCI ha sido menor de lo esperado.

Hubo otra novedad con el virus $\mathrm{A}(\mathrm{H} 1 \mathrm{~N} 1) \mathrm{v}$, ya que en el hemisferio norte se observaron ondas de mayor intensidad que las de los inviernos anteriores y en momentos diferentes a los habituales. Efectivamente, la onda pandémica se presentó en Galicia antes de lo usual aunque con una intensidad superior a la de los últimos años sólo observada con el registro del 061, ya que ni con el SXNOE ni con los registros de atención primaria se detectó. Esto se puede explicar porque la distribución etárea de las consultas está muy escorada hacia las edades más jóvenes.

Resulta coherente con todo ello la evolución observada en la proporción de muestras positivas para $\mathrm{A}(\mathrm{H} 1 \mathrm{~N} 1) \mathrm{v}$. La proporción de positivos más bajos en los grupos extremos de la vida, podría ser debido a una menor especificidad de la clínica en esas edades y la mayor preocupación por presentar complicaciones.

El objetivo fundamental establecido para los sistemas de vigilancia de la gripe en Gali- cia es el poder informar a los servicios sanitarios de la inminencia de una situación que pudiese desbordarlos, con el fin de que puedan prepararse para ello y, en este sentido, se considera que los sistemas que configuran la vigilancia en Galicia permitieron dar cuenta de dicho objetivo ${ }^{9}$, si bien es cierto que en una situación no muy exigente como resultó ser este primer momento de la nueva pandemia. En este sentido, es interesante destacar que todo ello sería mucho más difícil sin la puntual información proporcionada por diferentes agencias, especialmente de la ciudad de Nueva York, Reino Unido, Chile, Argentina, Nueva Zelanda y Australia, que permitieron establecer unos valores de referencia que, de no ser superados, como ocurrió, indicarían que no habría por qué temer un compromiso importante para el sistema sanitario.

De todos modos, el no disponer de una red centinela propia supuso un reto importante cuando se precisó saber si en Galicia habría ya, o aún no, transmisión comunitaria sostenida del nuevo virus. Para ello hubo que disponer de un sistema ad hoc, que cumplió sus objetivos, pero que no se puede saber si hubiese sido igual de efectivo de haber tenido que estar en funcionamiento mucho más tiempo, ya que habría podido suceder que, por agotamiento, hubiese fallado.

En resumen, los resultados observados avalan los sistemas de vigilancia empleados en Galicia, dada la homogeneidad existente en todos ellos, si bien cabría preguntarse la ventaja de mantener tantos sistemas diferentes cuando los resultados son similares en todos.

De esta manera, el teléfono de emergencias queda, una vez más, reconocido como un buen sistema de vigilancia de actividad gripal ya que, además de detectar el inicio de la onda, el pico y la duración de la misma, y permitir establecer niveles de intensidad, tendencia y difusión, al ser un sistema de vigilancia que proporciona los datos diaria- 
mente, permitió predecir el pico de la onda con un intervalo de dos semanas 9 , lo que facilitó el poder avisar a los servicios sanitarios para que se preparasen y activasen sus sistemas de alerta.

\section{AGRADECIMIENTOS}

Al personal médico hospitalario, a los servicios de medicina preventiva, a los microbiólogos, al personal del 061, a los médicos de atención primaria y al personal de epidemiología de los departamentos territoriales de sanidad, sin cuyo apoyo no se podría desarrollar la vigilancia de la gripe.

\section{BIBLIOGRAFÍA}

1. de Mateo S, Larrauri A, Mesonero C. La vigilancia de la gripe. Nuevas soluciones a un viejo problema. Gac Sanit. 2006;20(1):67-73.

2. Centers for Disease Control and Prevention (CDC). Swine Influenza $\mathrm{A}(\mathrm{H} 1 \mathrm{~N} 1)$ infections-California and Texas, April 2009. MMWR Morb Mortal Wkly Rep.2009;58:(16):435-7.

3. Novel Swine-Origin Influenza A (H1N1) Virus Investigation Team, Dawood FS, Jain S, Finelli L, Shaw MW, Lindstrom S, Garten RJ, Gubareva LV, $\mathrm{Xu} \mathrm{X}$, Bridges CB, Uyeki TM. Emergence of a Novel Swine-Origin Influenza A (H1N1) Virus in Humans. N Engl J Med. 2009;360:2605-15.
4. Servicio de Epidemiología. Boletín Epidemiolóxico de Galicia (BEG) Vol XXII/2009 N. ${ }^{\circ} 5$ maio 2010. Disponible en: http://www.sergas.es/MostrarContidos_N3_T01.aspx?IdPaxina=62622.

5. Fraser C, Donnelly CA, Cauchemez S, Hanage WP, Van Kerkhove MD, Hollingsworth TD, Griffin J, Baggaley RF, Jenkins HE, Lyons EJ, Jombart T, Hinsley WR, Grassly NC, Balloux F, Ghani AC, Ferguson NM, Rambaut A, Pybus OG, LopezGatell H, Alpuche-Aranda CM, Chapela IB, Zavala EP, Guevara DM, Checchi F, Garcia E, Hugonnet S, Roth C; WHO Rapid Pandemic Assessment Collaboration. Science. 2009 Jun 19;324(5934): 1557-61.

6. Itoh Y, Shinya K, Kiso M, Watanabe T, Sakoda Y, Hatta M, Muramoto $\mathrm{Y}$ et al. In vitro and in vivo characterization of new swine-origin $\mathrm{H} 1 \mathrm{~N} 1$ influenza viruses. Nature. 460, 1021-1025.

7. Ikonen N, Strengell M, Kinnunen L, Osterlund P, Pirhonen J, Broman M, Davidkin I, Ziegler T, Julkunen I. High frequency of cross-reacting antibodies against 2009 pandemic influenza $\mathrm{A}(\mathrm{H} 1 \mathrm{~N} 1)$ virus among the elderly in Finland. Euro Surveill. Volume 15, Issue 5, 04 February 2010.

8. Health Protection Agency. Pandemic (H1N1) 2009 in England: an overview of initial epidemiological findings and implications for the second wave. [Internet]. London: Health Protection Agency, 2009. Disponible en: http://www.hpa.org.uk/web/ HPAwebFile/HPAweb_C/1258560552857.

9. Servicio de Epidemiología. Listaxe completa de informes: 2009, semana 42. Disponible en: http://www.sergas.es/MostrarContidos_N2_T01.a spx?IdPaxina $=62575$. 